\title{
Palavras de agradecimento
}

Reynaldo Porchat

Não sei com que palavras deva iniciar este meu agradecimento.

E' tanta a generosidade que esplende nesta manifestação, muito mais de amizade do que de justiça; foi tão referta de bondade a palavra eloquente que se desatou em louvores á minha pessoa - louvores suspeitos porque vêm de um querido amigo, do velho professor que lhe quer muito: - que eu chego a vacilar sem saber como equilibrar-me na altura em que magnanimamente fui alçado.

Um simples professor, que deu aulas, e foi assiduo no cumprimento do seu dever, não merece destaque nem elogios.

Um dia pensei na honra insigne de fazer parte da douta Congregação desta Faculdade, á qual, quando estudante, me dediquei com todas as veras da minha simpatia e do meu carinho. Forrei-me de coragem para enfrentar um concurso. Logo de principio vi que não tive sorte, pois que não apareceu nem um outro concorrente, o que significava que eu teria de ser arguido pelos sabios mestres. Preparei a dissertação - "Posição juridica dos Estados Federados perante o Estado Federal".

Era em 1897, pouco tempo depois de proclamada a Republica. $O$ assunto era de momento, porque ainda, entre nós, havia alguns juristas e alguns politicos que sustentavam

(*) Resposta à saudação do Prof. Waldemar Ferreira, a 23 de outubro de 1948 . 
com Dubs e outros publicistas, a existencia de uma soberania dupla no regime federativo.

Uma carta que recebi de Martins Junior, o insigne : festejado mestre da Faculdade de Direito do Recife, deu-me vigoroso alento na defesa da doutrina, dizendo-me com $\mathbf{a}$ sua respeitavel autoridade, estas animadoras palavras: "ao ler a sua dissertação para o concurso, tive a impressão de quem, caminheiro isolado em um deserto, encontra viajor amigo que segue o mesmo destino".

Realizada a inscrição, foi feito o sorteio dos lentes que deveriam arguir-me. Teria a sorte me amparado então?

Em discurso que tive a honra de pronunciar desta tribuna, em 14 de novembro de 1928, em nome da Congregação, na cerimonia solene em que aqui foi colocado o busto do saudoso professor Brasillo Machado, esculpido em marmore por BRECHERET, tive a oportunidade de lembrar que esta Congregação possuia, no seu seio, uma turma de argumentadores temidos, que grangearam celebridade pelos recursos de uma tatica singular e os rigores de uma logica invencivel, como por exemplo, Benevides, armado com as subtilezas da sua metafisica; Joño MonteIro, de uma fogosidade sem par no ataque contra os defeitos das teses e os erros de português; Pedro Lessa, tempera de um profundo erudito servido por um verbo fluente e acelerado; Brasilio Dos SANTos, com uma dialetica de ferro e uma frieza de aço; JoÃo Mendes Junior, com o seu vasto saber de filosofo, aparelhado sempre com as perigosas distinções e subdistinções da escolastica; Brasilio MACHADo, suave e maneiroso, quase terno, mas que, iniciando o ataque em voz ciciada, como em idilio, intensificava-o e avigorava-o até constringir o arguido nas roscas de sua logica opressora, só o deixando no momento em que, pronunciada a sua conhecida expressão "estou satisfeito", - levantava-se na doutoral abrindo os braços em gesto largo enquanto o candidato ainda na tonteira do combate, e de olhos anuviados, enxergava naqueles braços abertos um simbolo perfeito da cruz em que passorz. os seus momentos de martirio. 
Para a minha arguição foram sorteados PEdro Lessa, João Mendes Junior, Brasilio Machado, Leoncio de Carvalho e Veiga Filho.

Os dois ultimos arguiram com brandura, deixando ao candidato tempo livre para defender as teses impugnadas.

Lessa e JoÃo Mendes arguiram com calor e rigorosamente. Não perderam um só minuto do tempo que lhes era concedido por lei. Só se detiveram quando o saudoso secretario Julio MAIA, esgotada a areia da ampulheta, bateu com ela energicamente sobre a mesa.

Brasilio não esgotou a hora. Advertiu, preliminarmente, que, tendo observado, nas arguições anteriores, que o candidato era habil em fugir ás dificuldades com que o afrontavam os arguentes, escolhera um assunto positivo e pratico, em que o candidato não poderia sofismar, e só estaria seguro quando se visse em frente da verdade comprovada: - Historia do Direito Nacional. E atacou, como falsa, a tese: "A invasão sarracena não produziu modificação no direito da peninsula iberica".

Não arguiu com energia. Antes com a doçura, que era um seu predicado caracteristico, doçura que, por uma verdadeira magia, se amoldava á sua dialetica invulneravel. Nas cadeias dessa dialetica foi adstringindo o candidato, que se defendera como pudera. Só o deixou quando, em meio do debate, exclamou sorridente e malicioso, com ar triunfante, o seu final costumado: "Estou satisfeito". Foi então que o candidato, ainda tonto da refrega, pôs-se a passear pelas arcadas, á espera do resultado do julgamento pela Congregação que, solenisada pelas negras becas, se recolhera ao salão nobre. $O$ primeiro lente que desceu as escadas foi Joño Monteiro, que, ao ver-me, acenou de longe, com um gesto largo e amigo, exclamando: — "Unanimemente".

Estava triunfante o candidato, que, por esse caminho, eriçado de espinhos, mas tambem suavisado de encantos, e iluminado de esperanças, alcançou a honra de fazer parte da emerita Congregação da Faculdade de Direito de 
São Paulo. Um lugar na Congregação é uma honra, mas é tambem um compromisso. Depois, foram as aulas realizadas com assiduidade. E os exames julgados com justiça, mas sem rigor. Vieram as solenidades academicas, em que o novo professor foi sempre verdadeiramente e sinceramente um academico: os 11 de Agosto, as recepções de personagens notaveis, do Brasil, da Europa e da America, a dos estudantes de Lisboa, a dos estudantes de Coimbra, que, prestando homenagem ao professor que acabava de sauda-los, praticaram a cerimonia, que era estranha entre nós, de se despojar de suas capas e estende-las sobre o chão como tapete a fim de que o orador, ao deixar a tribuna, sobre elas passasse. Homenagem singular, mas altamente expressiva.

E nessa nobre lida tão referta de prazeres e de alegrias, onde a idade se ilude e como que a velhice remoça aos influxos da alacridade dentro desta casa que é um monumento imperecivel de glorias, a minha alma foi aos poucos sendo tocada, em sua essencia, por tão intenso sentimento de amizade, de dicação, de devoção mesmo, que, embora daqui afastado materialmente, ha alguns anos, é nela que eu vivo sempre como parte sua, orgulhosamente talvez, onde quer que me encontre, a ouvir constantemente as notas eletrizantes do hino academico a cujo ritmo balança 0 nosso estandarte.

Mas, ainda que apartado desta intima e fecunda convivencia, por motivo da disponibilidade que a lei me facultou, a minha atividade não abandonou a causa do ensino, á qual, até hoje me dedico, lutando, muitas vezes arduamente e considerando-me sempre o legitimo representante da douta Congregação que me elegeu, em 1911, seu representante como membro do Conselho Superior do Ensino criado pela lei Rivadavia e inaugurado sob a presidencia de Brasillo Machado.

Eleito por esta douta Congregação, sinto que não ha melhor oportunidade do que esta "para dar contas" do que fiz como seu representante. O professor de São Paulo 
sempre fiel ao que aqui aprendeu neste proveto meio, e com os velhos mestres, manteve integralmente a linha dos principios do direito e da moral que nesta casa se observam.

As leis foram mudadas: mas minha pessoa foi sempre conservada no seu cargo, não por mim, mas em homenagem a esta gloriosa Faculdade que me elegeu. Aí labuto efedivamente até hoje, - ha mais de 36 anos, - onde os Conselheiros, meus distintos colegas, me honram, por sua eleição anual, conservando-me na presidencia do hoje denominado Conselho Nacional de Educação. Dań, desse alto posto central do país, contemplo a evolução, o desenvolvimento e as perturbações do ensino superior e do secundario causadas por esse prurido de legislar que caracterizou o governo ditatorial, inundando o país com a abundancia dos seus decretos-leis inoportunos, inexequiveis e contraditorios. Por mais que eu haja, repetidamente lembrado, no exercicio da minha função, a advertencia salutar de TAcito aos Romanos, nos Anais, - "plurimae leges corruptissima republica" - a invasora maré legislativa não encontrou obstaculos. Falava um passadista impenitente invocando velhissimo escritor classico. E os decretos-leis-modernistas proliferaram, multiplicaram-se, embaraçaram-se formando esse entrançado e inextricavel cipoal legislativo que é hoje a nossa legislação sobre o ensino, o qual á moderna, é denominado educação.

Depois que a infeliz reforma Rivadavia, de 1911, vibrou golpe de morte no ensino superior e no secundario, dispensando a prova de capacidade para o exercicio das profissões liberais, e abrindo campo livre ao mercantilismo de institutos de ensino e de diplomas, ainda houve uma reação salutar, que veio ao encontro dos clamores unissonos de toda a população sensata do Brasil - foi a reforma sabiamente elaborada por Carlos Maximiliano, em 1915, insigne jurisconsulto, então ministro do presidente Venceslau Brás.

Ambos nos deram a honra de visitar esta Faculdade, o primeiro em 1915, e o segundo em 1918. E eu tive a 
satisfação de ser quem os saudara desta tribuna em nome da Congregação.

Esta reforma repôs o ensino na sua posição oficial, que The imprimiu sempre o mais respeitavel lustre, e permitiu, paralelamente, a criação de institutos livres contanto que fossem eficientemente fiscalizados.

Estavam sendo lentamente curados os males oriundos da reforma de 1911.

O que não poderia ser curado, nem tolerado, eram os resultados do mercantilismo fundado na imoralidade que lastrava. Mudado radicalmente o regime politico, sobreveio nova reforma, extensa e ostentosamente elaborada, a reforma de 1931.

Não era de todo má, apesar dos seus graves defeitos, e poderia produzir bons resultados se praticada com criterio e com autoridade.

Mas foi inaugurado o sistema das "retificações", das "alterações" e das "novas redações" de artigos de decretos anteriores. Foi um descalabro. Daí por diante não houve mais lei com carater de permanencia.

Este sistema, que proliferou para atender aos pedidos de interessados, foi uma praga que medrou e corrompeu o ensino. Implantou-se o casuismo na legislação. $\mathrm{E}$ esse sistema teve o seu apogeu no decreto-lei n. 5.545 de junho de 1943.

Eram inumeros os alunos e os proprietarios de estabelecimentos que se tinham aproveitado da lei Rivadavia, e que, a despeito de reforma Maximiliano, continuaram teimosamente a explorar o que tinha sido denominado ensino livre.

Em tempos de ditadura criam-se e multiplicam-se os pedidos de empenhos. As secretarias e os ministerios enchem-se de gente de toda casta, e os aduladores pululam, seduzindo e atraindo a atenção das autoridades que não resistem á concessão de favores. (Leia-se Guglielmo FerRERo - "Grandezza e Dacadienza di Roma"). 
Sob o peso da massa dos que pediam sem ter direito nenhum que os amparasse, a autoridade accedeu, e promulgou o referido decreto-lei, cuja ementa bem o define, exarada nestes termos:

"Estabelece as medidas destinadas á regularização da vida escolar "de alunos que frequentam ou hajam frequentado curso superior não reconhecido, e bem assim de diplomados por curso superior igualmente não reconhecido".

0 artigo $1 .^{\circ}$ dispõe:

"Qualquer aluno de curso superior que, tendo funcionado sem reconhecimento, "esteja ou venha a ser proibido de funcionar, poderá requerer ao Departamento Nacional de Educação transferencia para curso congenere de estabelecimento federal ou reconhecido".

Para obter essa transferencia eram exigidas as sumarias provas de habilitação indicadas nos subsequentes artigos do decreto.

E o paragrafo $1 .^{\circ}$ do artigo $1^{\circ}$, para maior segurança dos favorecidos, concedeu-lhes, contra a lei vigente expressa, este privilegio protetor, como se merecessem mais do que os estudantes que limpamente frequentam as escolas oficiais ou as reconhecidas:

"Não prejudicará a transferencia, em nenhuma hipotese, o principio de limitação de matricula".

Note-se que estava em pleno vigor o decreto-lei n. 421, de 11 de maio de 1938, que proibia que se organizassem e funcionassem no país institutos de ensino que não estivessem previamente autorizados pelo governo federal mediante exibição de provas de competencia e de moralidade apreciadas pelo Conselho Nacional de Educação.

Para dar execução aos favores concedidos pelo decretolei 5.545 e pelos outros que o completaram no mesmo sentido, foi criada, adrede, uma Junta Especial do Ensino Livre com os poderes que lhe conferiu o decreto-lei $\mathrm{n}$. 7.401, de 20 de março de 1945.

A facilidade com que foram concedidas transferencias e diplomas chegou a tal ponto, que provocou severas criti- 
cas; e um dia, em 28 de dezembro de 1945, o Instituto da Ordem dos Advogados, Conselho Seccional de Belo Horizonte, expediu um oficio ao Sr. Ministro da Educação dizendo-se vivamente impressionado com a validação de diplomas autorizada pelo decreto-lei n. 7.401, de 1945, o que tornava possivel o ingresso, na Ordem, de pessoas que notoriamente não estão preparadas para o exercicio da profissão, e apelando calorosamente para sua exa. a fim de que fosse revogado o decreto que instituiu a Junta.

Tendo sido o assunto submetido ao Conselho Nacional de Educação, para emitir parecer, aprovou este unanimemente, em sessão publica, o parecer n. 170 de sua comissão de legislação, datado de 23 de agosto de 1946, no qual, depois de fazer uma exposição dos maus resultados da aplicação dos tais decretos, concluiu opinando que, como medida de alta conveniencia para a profissão e para o ensino, fosse atendido o pedido da Ordem dos Advogados, e que não só fosse revogado o decreto-lei n. 7.401, criador da Junta, mas tambem os decretos-leis ns. $5.545,6.723,8.896$ e 6.897 , que dispunham sobre a materia da validação de cursos e de diplomas.

Esse parecer, apesar de haver sido unanimemente aprovado, não foi homologado pelo Sr. Ministro, que o devolveu ao Conselho, para que pudessem ser reconsiderados os termos em que forra exarado.

Distribuido pelo presidente a novo e douto relator, a fim de atender á recomendação ministerial, voltou o processo com o parecer n. 228, no qual, depois de declarar que fôra reexaminado o assunto, concluiu mantendo o parecer anterior. Aprovado unanimemente este, como houvera sido o primeiro, não foi, entretanto, homologado. O Sr. Ministro expôs os fundamentos da sua discordancia, e mandou arquivar o processo, em 3 de outubro de 1946. Por esse motivo, os dois pareceres não foram publicados no "Diario Oficial", como era de costume.

Afinal, como terminara no fim do ano de 1946 o ultimo prazo concedido para o funcionamento da Junta, o atual 
Ministro, cautelosamente, atribuiu a competencia para a execução e para a liquidação da materia regulada pelos aludidos decretos-leis ao sr. diretor do Ensino Superior, que é tambem distinto membro do Conselho, e que está dando cumprimento á sua missão com a maior solicitude e acostumado escrupulo, apurando os casos e depurando as irregularidades inumeras existentes.

Mas, embora restaurado o regime constitucional, já surgiu, na Camara dos Deputados, um projeto de lei, a pedido dos interessados, visando o mesmo fim de conceder os mesmos favores aos que nunca estudaram em escolas autorizadas nem reconhecidas, isto é, aos que até hoje se mantêm em rebeldia contra as exigencias do decreto-lei n. A21, de 11 de maio de 1938.

Abre-se, de novo, a falsa porta por onde passem e alcancem diplomas validos aqueles que nunca estudaram seriamente, e que, propositadamente, nunca se sujeitaram ás exigencias legais.

Note-se bem: Estando em vigor o decreto-lei n. 421 desde 1938, e estando a findar o ano de 1947, - 9 anos decorridos - fôra bem melhor que tais pretendentes, em vez de andarem a solicitar escandalosos favores aos legisladores, se dessem ao trabalho de submeter-se seriamente ás exigencias da lei, pois, se o fizessem, já estariam hoje com os seus cursos regularmente feitos e terminados.

Preferem o favor pedido humildemente, ao trabalho de conquistar altivamente, com estudo regular, um valido e dignificante diploma.

$\mathrm{E}$ tal projeto, que visa restaurar o nefasto regime das validações, ora extinto pelo decurso do prazo que lhe fôra assinado, já obteve parecer favoravel da comissão de cultura da Camara!

Mas o Congresso Nacional - preocupado com o caso da cassação dos mandatos comunistas, de modo a resolver a anomalia de, cobertos pelas imunidades, se manterem no Parlamento, pregando idéias condenadas pela Constituição, representantes de um partido cancelado como ilegal pelo 
Superior Tribunal Eleitoral - - achará tempo ainda para votar leis de favores aos que nunca estudaram, contribuindo, assim, para a decadencia do ensino em pleno regime constitucional?

Nesta ilustre Congregação têm assento eminentes professores que são deputados federais. Oxalá que, com o amor que consagram a esta Academia, e com a sua dedicação á causa do ensino, não desprezem este brado de "alerta" que lhes dirige confiante o velho professor cinquentenario.

Quanto ao ensino secundario, a situação é tambem de confusão e decadencia.

Nota-se, logo ao primeiro golpe de vista, que o estudo, em regra, não é proveitoso. Atordoados os estudantes com a quantidade de materia que se lhes impõe, com o seu estudo dividido em series e ciclos, a consequencia é serem dominados pelo desanimo.

A este ponto tambem tenho lembrado a advertencia de um classico - o velho Montaigne - quando aconselha aos educadores que lhes cumpre formar "cabeças claras" e não "cabeças cheias"

Mas para os modernos legisladores estes conceitos são antiquados. A pedantocracia pedagogica precisa ostentar coisas mais complicadas.

Antigamente, até aos primeiros tempos da Republica, os pretendentes a cursos superiores se preparavam nas disciplinas que eram denominadas "preparatorios", e, com essa bagagem humanistica, faziam com exito a sua carreira miIhares de estudantes que deram ao Brasil essa galeria opulenta de notaveis vultos que figuraram na sua historia, quer como estadistas dignificando o nosso parlamento, quer como medicos, engenheiros, jurisconsultos, homens de ciencia e homens de letras, aureolados de indiscutivel reputação, compondo as respeitaveis Congregações das Faculdades de Medicina do Rio de Janeiro e da Bahia, da Escola Politecnica, das Faculdades de Direito de S. Paulo e do Recife, cujo prestigio até hoje se impõe á nossa admiração e respeito. 
Não preciso citar nomes, porque, se o fizesse, teria de compor uma lista interminavel de personagens notaveis $\mathrm{e}$ benemeritos do Brasil.

O ensino secundario era simples, e, portanto, proveitoso. O Colegio Pedro II era um modelo admiravel e fecundo, com tradição respeitadissima. Hoje, consubstanciado na reforma operada pelo decreto n. 4.244, de 9 de abril de 1942, denominado "Lei Organica do Ensino Secundario", com seus inumeros aditivos, não podia o ensino ser vasado em lanços de simplicidade e clareza. Foi preciso ostentar forma moderna. Todos sabiam o que era um ginasio, ou um colegio, na linguagem portuguesa usual e tradicional. Era preciso mudar. Então mudou-se não só a substancia do curso como tambem o significado das palavras. $\mathrm{O}$ ginasio, que sempre teve um curso de cinco anos, precisou ser reduzido a quatro anos, constituindo o denominado primeiro ciclo. E inventou-se o colegio, com um novo sentido, destinado a dar, em seguida ao ginasial, os dois cursos de segundo ciclo, dividido em curso classico e curso cientifico, cada um com a duração de três anos.

Note-se que as disciplinas que se estudam no curso classico são as mesmas que se estudam no curso cientifico (art. 13), salvo o grego e o latim que somente se ministrarão no curso classico, e o desenho, que se ensinará somente no curso cientifico. Mas pode ser feito o curso classico sem o estudo do grego, á vontade do aluno (art. 163). Os exames tambem foram definidos e divididos em três ordens com denominações diversas: - de admissão, de suficiência, e de licença (art. 26). Os de suficiencia são os mesmos que sempre foram conhecidos com o nome de exames de promoção, isto é, os que habilitam o aluno a matricular-se na serie imediata. E os de licença, não são senão aquilo mesmo que na linguagem vulgar sempre se chamou exame final ou de conclusão de curso (arts. 47 e 53).

Essa complicação em materia de exames, introduzida pela Lei Organica, foi julgada inutil pelo proprio Governo 
Federal, pelo decreto-lei 9.303, de 27 de maio de 1946, que, "considerando que os exames de licença ginasial e de licença colegial não foram até hoje realizados em face de dificuldades de ordem varia decorrentes das condições atuais do sistema educacional do país; e considerando que a inaplicabilidade desse sistema parece evidenciada pela revogação anual e sistematica dos exames desde a vigencia da Lei Organica; e considerando mais que não convem á boa pratica administrativa a revogação de medida legal somente quando se apresenta o momento de ser a mesma aplicada, e que só no futuro, quando outras e mais favoraveis forem as condições do sistema educacional do país, é que poderão ser restaurados sobre novas bases"; suprimiu tais exames, e determinou que a habilitação dos alunos matriculados na 4." serie do curso ginasial, ou ou na $3 .^{\mathrm{a}}$ serie do curso colegial, fosse feita com observancia do regime dos exames de suficiencia relativos ás demais series no curso secundario, dando-se, aos que conseguirem habilitação por essa forma, certificado de conclusão do curso ginasial ou do curso colegial.

Por fim veio o art. 91, repetição do famoso art. 100 do decreto n.21.241, de 4-4-1932, que abriu portas largas áqueles que, sendo maiores de 19 anos, podem obter certificado de licença ginasial, em consequencia de estudos realizados particularmente, sem a observancia do regime escolar exigido pela lei, certificado que lhes dá os mesmos direitos que têm os menores dessa idade, que estudaram os quatro anos do ginasio obedientes ao respectivo regulamento. E assim, por meio desse "regime de exceção", como se expressa a propria lei, se dá por terra com toda a fiscalização do estudo. ginasial, porque se acena ao menor com essa facilidade de estudar livremente onde e como quiser, para, aos 19 anos. fazer todos exames e, com essa aprovação sumaria, ficar com direitos iguais aos dos que suportaram os 4 anos do curso fiscalizado. 
E para agravar o mal, o decreto-lei 8.347, de 10 de dezembro de 1945, que deu nova redação a muitos artigos da lei Organica de 1942, chegou ao extremo de reduzir a 17 anos a idade de 19 que era exigida pelo art. 91 para poder o estudante gozar do favor de exceção. Este famoso art. 91, uma das valvulas abertas para a decadencia do ensino secundario, goza de tanta simpatia da parte dos que governam, acessiveis ás cartas de recomendação, que ainda agora foi votada pelo Congresso Nacional, e sancionada pelo sr. presidente da Republica, a lei n. 15, de 7 de fevereiro de 1947, que permite a tais estudantes, assim favorecidos, não só se inscrevam para a realização de exames de 2." epoca quando inabilitados na $1 .^{\mathrm{a}}$, ou quando não se houverem inscrito, como tambem lhes concede o grande favor de poderem livrar-se de prestar tais exames em institutos federais ou equiparados, como era exigido, podendo prestá-los em qualquer estabelecimento mantido pelos Poderes Publicos Municipais ("Diario Oficial” de 8-2-1947).

Eis aí uma sintese do que é hoje o sistema legal do ensino secundario instituido pela Lei Organica de 1942 e os inumeros decretos-leis que sucessivamente a modificaram.

Senhores :

Ao fazer estas considerações criticas que estou expondo, não pareça que há, da minha parte, qualquer intuito malefico ou maldizente.

O meu escopo é mostrar que, diante da decadencia do ensino superior e do secundario, percebida e sentida por todos como um grande mal patente, o Conselho Nacional de Educação, de que tenho a honra de ser o presidente, não tem nenhuma responsabilidade. A sua ação tem sido, ao contrario, de tenaz resistencia contra os favores liberalizados pelos inumeros decretos-leis que são a causa do lamentavel fenomeno.

E' comum ouvir perguntas a respeito do que faz o Conselho em face de semelhante situação. 
Mas tais perguntas somente podem partir de quem não conhece a situação legal e a limitada competencia do Conselho.

E' oportuno explicá-lo aqui, com o fim de o defender.

E' que o Conselho não tem função legislativa, nem mesmo é ouvido sobre os projetos de lei que se elaboram no Ministerio.

Certa vez, por exceção, foi incumbido de organizar um projeto completo de reforma do ensino para ser apresentado ao poder legislativo, no regime constitucional de 1934, com o fim de servir de base ao trabalho que deveria ser elaborado pelo Congresso.

O Conselho, depois de exaustivo trabalho, e fatigante assiduidade em sessões realizadas diariamente, desempenhou-se da incumbencia, e apresentou o resultado do seu esforço ao Ministro. Sobreveio depois o golpe ditatorial de 1937, e o trabalho elaborado pelo Conselho nunca saiu da gaveta do Ministro.

Sucederam-se, com incrivel fecundidade, os decretosleis - "plurimae leges" - para atender a cada pedido de um recomendado; multiplicaram-se as derrogações $\mathrm{e}$ as novas redações de artigos e paragrafos; e o resultado foi criar-se, na esfera do ensino, essa confusão caracteristica de uma legislação fragmentaria e casuistica, que mesmo os peritos não conseguem entendê-la e harmonizá-la em suas inumeras contradições.

A função do Conselho é a de dar pareceres sobre as duvidas ocorrentes por ocasião da aplicação dessas leis quando o Ministro e altas autoridades do ensino para isso lhe remetam os respectivos processos. $E$ os pareceres não têm eficacia senão depois de homologados pelo Ministro.

E' essa a função do Conselho: emitir parecer interpretando e aplicando essa tormentosa legislação. "Durum officium".

$\mathrm{E}$ é tão grande o numero de processos em que as duvidas avultam, que o Conselho trabalha durante mais 
de seis meses cada ano, e ainda sobram processos que aguardam nova reunião para serem estudados.

Meus senhores:

Mesmo no exercicio dessas funções do Conselho, tive a honra de ser convocado por Armando de Salles Oliveira, - esse paulista de alma pura, que deixou em sua curta vida um traço luminoso, revelando-se insigne estadista, realizador e clarividente, - para exercer o cargo de Reitor da Universidade de São Paulo, que ele, com elevada visão, criou e organizou. E tive, então, a fortuna de poder voltar a este ambiente para mim tão cheio de encantos, e aí conviver, de novo, em contato com os meus amigos e colegas.

$O$ que foi essa afortunada criação, para o engrandecimento do ensino em São Paulo, não é preciso dizê-lo aqui. Todos sabem e sentem o que foi essa notavel reforma realizada pelo inesquecivel paulista, dentro da qual se destacou como promissora novidade a Faculdade de Filosofia, Ciencias e Letras, organizada com o mais alto criterio e constituida com selecionado corpo docente do qual faziam parte reputados professores com pratica do ensino nos paises estrangeiros e que aqui formaram, com distintos professores brasileiros, um conspicuo corpo docente, que despertou a admiração da parte de outros Estados da Federação.

Foi um periodo aureo do ensino superior paulista. Foi uma fase de viva animação. E eu ainda sinto as alegrias que me rejuvenesciam como uma florescencia emanada do contato feliz em que pude gozar da convivencia seleta com os eminentes mestres de todas as escolas superiores, e fruir o doce convivio proveitosissimo nas secções do Conselho Universitario.

Alem das inovações introduzidas com a criação do novo instituto, multiplicaram-se as visitas de alto valor intelectual, da Europa e da America, e eu tive a feliz oportunidade, na qualidade de Reitor, de apresentar-lhes as saudações da Universidade. 
Tive tambem a honra de, como Reitor, tomar parte no Congresso das Nações Americanas que se reuniu em Paris, organizado pelo Instituto de Estudos Americanos sob o patrocinio da Universidade de Paris e do Comité France Amerique, onde apresentei o Aperçu Sur L'Influence Française Au Brésil, que constituiu o numero 18, de 1938, dos Cahiers de Politique Etrangère, dirigidos por GABriel e Louis JaraY.

Pude notar a grande consideração que foi dispensada á Universidade de São Paulo, e de concorrer quanto me foi possivel, em nome desta, para estreitar as relações intelectuais entre a França e o Brasil.

Releva salientar aqui, como homenagem devida e como um culto de gratidão á sua memoria saudosa, o nome do insigne professor Georges Dumas, da Sorbonne, que, pela sua autoridade e pela sua eficaz influencia, muito fez por cimentar o comercio intelectual tão proveitoso á nossa Universidade.

Mantive-me no exercicio desse cargo, procurando bem servi-lo até que, em virtude de mudanças que sobrevieram na administração do Estado por determinação do Governo Federal, impus-me o dever de exonerar-me.

Ex-professor, e ex-reitor, considero-me sempre com a marca inapagavel dessas honrosissimas investiduras. E esse passado encantador e inesquecivel, cuja recordação me anima e me aviventa, instila-me ainda alento para lutar, sem fadiga, em pról da causa do ensino - força impulsionadora do engrandecimento do Brasil.

Agradeço ao magnifico reitor e á douta Congregação da Faculdade de Direito esta imponente homenagem que tanto me honra e me comove.

Senhores:

Esta manifestação de simpatia com que me honra o colendo Tribunal de Justiça de São Paulo, aqui representado pelos conspicuos Desembargadores presentes, é mais 
do que a expressão das felicitações com que me desvanecem pela data do cinquentenario que hoje se festeja. E' um premio com que eu me sinto condecorado como compensação do longo tempo de labor em que, ensinando aos moços, preguei sinceramente os sãos principios do direito puro. Porque não há nada mais belo nem mais confortador, para quem passou uma longa parte da vida explicando o direito, do que vê-lo concretizado nos sabios acordãos dos Tribunais, onde os juizes, como os sacerdotes, praticam a justiça correspondendo ao mesmo sentimento que levara Ulpiano a dar-nos, a todos nós, cultores do direito, a denominação de sacerdotes - cujus merito quis nos sacerdotes appellet: justitiam namque colimus et boni et aequi notitiam profitemur, aequum ab iniquo separantes, licitum ab illicito discernentes (fr. 1 e $\S 10^{\circ}$ - de just. et jur. (1-1).

Se alguns destes preclaros Desembargadores, que ainda estão no viço da juventude, sofreram as impertinencias de um professor exigente, aqui estão eles hoje elevados á altura de mestres, recompensando com este julgamento, repassado de bondade e de eloquencia, aquele que da catedra em que era investido de autoridade, passou a pleitear causas nos auditorios debaixo da autoridade muito mais imponente desses que são verdadeiros super-homens, porque nessa altura, em que a lei os coloca, exornando-os com uma aureola onde a toga inconsutil se reveste de um nimbo sagrado, é que eles têm o poder de proferir sentenças julgando os homens.

E' com religioso respeito que eu agradeço ao Egregio Tribunal, tão justamente apontado como um modelo na alta esfera do poder judiciario da Republica.

Agradeço ao Conselho Nacional de Educação por contribuir para a alta significação desta solenidade com a presença do seu digno representante, o Conselheiro Jurandir LodI, que é tambem o Diretor do Ensino Superior no Ministerio da Educação, cargo que tem sabido honrar e enaltecer. 
pelo seu trabalho arduo, pela sua independencia e pelo seu escrupulo.

Agradeço aos ilustres representantes do corpo academico (atuais e antigos alunos) cujas eloquentes orações me bateram forte como uma onda de saudade, impondo-me, irresistivelmente o desejo de repetir, nesta altura da vida, aquilo que dissera aos moços no tempo da minha feliz e fraterna convivencia com eles: Oh! alma da mocidade! Como é belo contemplar a tua imponente imortalidade: Dos tempos que se foram ao tempo que se passa, dos principios do seculo $\mathrm{XIX}$ ao meado do seculo $\mathrm{XX}$, aí estás, sempre firme como a sintese soberba de uma vida inextinguivel, guardando as gloriosas tradições da velha casa do Direito, que se concretiza neste nome resplandecente e imorredouro - Academia de São Paulo. Tua coragem e o teu vigor não podem esmorecer jamais porque tens de sustentar um passado que é um escrinio de gloria e tens de perlustrar um futuro em que o Onze de Agosto rebrilhe constante com as suas fulgurações inextinguiveis.

Se é verdade que já desapareceram grandes individualidades que por aqui passaram debaixo deste teto, onde entoaram as canções da sua juventude, tambem é certo que as gerações se substituem ininterruptamente na sucessão contínua das idades, mas não se extingue o substratum geral da coletividade, porque, no dizer de Lucrecio, as perdas de uma parte se realizam para enriquecer a outra parte, e a luz vivificadora se transmite de mão a mão como na carreira dos jogos sagrados de Atenas o facho luminoso da vida - "et quasi cursores, vitae lampada tradunt".

$\mathrm{E}$ agradeço a todos quantos aqui estão contribuindo para o brilho desta solenidade, dando provas de uma amizade que me prende no elo inquebrantavel desta expressão, que é vulgar, mas que exprime toda a sinceridade de um coração agradecido: - muito obrigado. 